
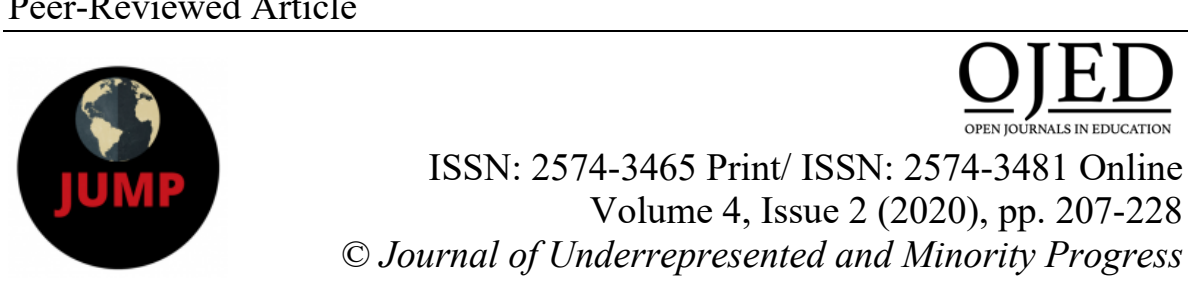

ISSN: 2574-3465 Print/ ISSN: 2574-3481 Online Volume 4, Issue 2 (2020), pp. 207-228 (C) Journal of Underrepresented and Minority Progress http://ojed.org/jump

\title{
Exploring Perceptions of Effective Leadership Practices of Presidents of Historically Black Colleges and Universities
}

\author{
Sydney Freeman Jr. \\ University of Idaho, USA \\ Robert T. Palmer \\ Howard University, USA
}

\begin{abstract}
Anchored in the anti-deficit approach, this manuscript investigated perceptions of effective leadership practices of presidents at historically Black colleges and universities (HBCUs). This manuscript provides a unique contribution to the literature by utilizing a general qualitative research approach to learn from a diverse set of voices of leaders and scholars within this sector that serve in various roles (e.g., Deans, Vice Presidents, and scholars) or who study leadership at these institutions. The study found that effective leaders at HBCUs generally have success across two categories experiential skills and professional knowledge. This study adds to the paucity of literature in this area by expanding and complicating our understanding of effective leadership practices of presidents at $H B C U$ s.
\end{abstract}

Keywords: College \& University Presidents, Effective Leadership, HBCU. 


\section{INTRODUCTION}

Historically Black Colleges and Universities (HBCUs) have been controversial institutions from their founding (Gasman \& Hilton, 2012). These institutions established for the specific purpose of educating Black students have been and continue to be under attack. They historically have been under resourced and received less support from philanthropist, nongovernmental agencies, and foundations (ACE/UNCF, 2019). Presidents of these institutions have had to navigate a quagmire of issues such as negative and racist commentary from press (Freeman \& Gasman, 2014), lagging infrastructures, lack of degree offerings, challenges with student completion rates, unstable finances, dearth of students' ability to pay tuition, and unfavorable federal and state policies, such as performance-based funding and attempts to dismantle the Parent Plus Loan (AGB, 2014).

In general, while many higher education institutions today face some of the challenges identified above, HBCUs have the added pressure of constantly receiving criticism for poor leadership practices (Gasman, 2012; Schexnider, 2017; Stuart, 2016, 2017; Watson, 2013). Specifically, the media, which view HBCUs as monolithic, frequently discuss the leadership struggles and challenges of HBCU presidents (Harris, 2017; Stuart, 2016, 2017; Watson, 2013). Similarly, scholars may have unintentionally perpetuated this narrative of poor leadership among HBCU presidents. While the literature is saturated with discussions of poor leadership practices among HBCU presidents, using an anti-deficit approach, this article seeks to shed light on contemporary and effective leadership practices for presidents of HBCUs.

Harper (2010) asserts that the anti-deficit framework "is mostly about the questions researchers ask. Implicit in an important overarching assumption: those who endeavor to improve success ... would learn much by inviting whose who have been successful to offer explanatory insights into their success" (p. 72). Given the historically negative narrative surrounding the role of the HBCU presidency, we sought to examine effective and contemporary leadership practices of HBCU presidents.

Others agree with the premise of this article rooted in the anti-deficit approach in order to help change the narrative about HBCU leadership. For example, the Center of Minority Serving Institutions at Rutgers University produced a report contextualizing the skills effective leaders of HBCUs need in the 21st Century (Esters et al., 2016). Moreover, other researchers have discussed successful leadership practices for HBCUs presidents (Freeman et al., 2016). However, most of this work is anecdotal (e.g., Esters et al., 2016; Lomotey \& Covington, 2018). As such, there is a limited amount of empirical 
research documenting successful leadership practices of HBCU presidents (Freeman et al., 2016; Freeman \& Gasman, 2014). As the authors of this study, we recognize as Maxwell (2019) states, "everything rises and falls on leadership" (para. 1). In the context of this manuscript that means that the success of HBCUs are often most determined by the quality of leaders at the helm of these institutions. This study seeks to explore the practices perceived to be important for HBCU presidential success.

With this in mind, the purpose of this study was to discuss contemporary and effective leadership practices for HBCU presidents. Data from this current study emerged from a larger study on contemporary leadership practices at HBCUs. The central question that guided this study was: What are effective and contemporary leadership practices employed by leaders of historically Black colleges and universities? This study is important because past studies have examined unsuccessful leadership for HBCU presidents. For example, Palmer and Freeman (2019) found that unsuccessful HBCU presidential leadership was based on a lack of technical skills (including having a vision or mission, innovating, possessing business skills, and demonstrating financial skills) and negative dispositions (evidenced by authoritarian leadership, negative character traits, or failure to understand institutional culture) (p. 4). In this context, successful leadership would therefore be the opposite. While a number of themes emerged from this larger study, in this current article, we discuss one of those themes, that is, perceptions of effective leadership practices of HBCU presidents. Engaging in this discussion and documenting these practices are critical to helping to change the narrative regarding HBCU leadership.

\section{LITERATURE REVIEW}

HBCUs were established after the Civil War to educate the newly freed Africans forcibly brought to America. Unlike other Minority-Serving Institutions (MSIs), HBCUs were not borne out of shifting demographic trends (Preston \& Freeman, 2019). MSIs such as, Hispanic Serving Institutions and Asian American and Native American Pacific IslanderServing Institution (AANAPISI) are colleges that were initially established to serve White students. These institutions have gained recognition as MSI based on growing populations of students of color. HBCUs are different as they were initially established with the express purpose of educating Black students. The Higher Education Act of 1965 defines, these institutions, "as any historically black college or university that was established prior to 1964, whose principal mission was, and is, the education of black Americans" (U.S. Department of Education, 2020, para. 1). Thus, once a HBCU is closed, a new one cannot be established. While this is the case, since their founding, in the mid to late 1880 s, scholars assert some HBCUs have been besieged by 
leadership challenges, which has resulted in their closure (Schexnider, 2017). To date, close to 20 HBCUs have closed their doors (Suggs, 2019).

Indeed, scholars have expressed that while there are a variety of contributors to the closure of a HBCU, one of the most salient is poor leadership, which is linked to issues, such as financial mismanagement, loss of accreditation, attrition of students and faculty, and turnover of presidents (Lomotey \& Covington, 2018; Schexnider, 2017). In an interview with Diverse Issues of Higher Education, Walter Kimbrough, president of Dillard University, lamented the fact that 38 HBCUs have appointed a new president since 2011, and as of 2014, nine of those were no longer in office (Transforming Leadership, 2015). Moreover, in 2016 at least four HBCU presidents were fired or resigned because of concerns from their governing boards about the efficacy of their leadership. Scott and Hines (2014) explained, "Over the past twenty years, across most HBCUs, there have been multiple cases detailing the failure of leadership" (p. 1133), which contributed to the fiscal management that resulted in the closure of Morris Brown. They also asserted, "Dysfunctional leadership and institutional traditions dominate at the majority of HBCUs, impeding the process and demanding specific strategies that address certain elements of academic culture (i.e., shared governance)" (p. 1133).

The instability of leadership among HBCU presidents has provoked concerns among HBCU stakeholders (Kimbrough, 2016). In response, there is a paucity, but burgeoning amount of literature on the college presidency at HBCUs. Some of this scholarship has focused on shared governance (Lomotey \& Covington, 2018), grooming the next generation of presidents (Freeman \& Gasman, 2014), and the board of trustees (Commodore, 2017). Nevertheless, as noted, there is a scarcity of scholarship on effective leadership practices for HBCU presidents (Esters et al., 2016). For example, the report discussed earlier by the Center for Minority Serving Institutions, provided a contemporary view on effective leadership practices for presidents at HBCUs (Esters et al., 2016).

Specifically, some of the practices discussed in this report included the importance of HBCU presidents understanding policy, particularly around funding, using data to inform decision-making, and being familiar with the accreditation process and ways to promote student engagement. This report also underscored other important qualities, such as the willingness of HBCU presidents to develop collaborative partnerships with other MSIs and predominantly White institutions and having an expertise in fundraising and institutional finance (Esters et al., 2016). Another important skill HBCU presidents should possess, according to Esters and colleagues (2016), is the ability to engage a variety of stakeholders and developing positive relationships with the board of trustees. 
Furthermore, Freeman et al. (2016) added to the conversation on characteristics for successful HBCU presidents. Specifically, by conducting qualitative interviews with HBCU presidents, board of trustees, and presidential consultant firms, they developed a list of essential skills for HBCU presidents. Many of their findings echoed those of Esters et al. (2016). Moreover, in a chapter that criticized HBCUs for lacking culturally relevant education in their curricula, Lomotey and Covington (2018) discussed not only the challenges to successful leadership for HBCU presidents, but they also provided a litany of strategies HBCU presidents should implement to be effective in their roles. Some of these included focusing on fundraising, hiring the right people, and avoiding an autocratic leadership style.

\section{RESEARCH METHOD}

We utilized a general qualitative approach to understand the patterns of effective leadership for HBCUs. This approach allowed us to gain insight into experiences and perspectives of participants related to effective leadership at HBCUs. By focusing on the phenomena of effective leadership practices, we gained a greater understanding of how participants viewed effective leadership from various levels of the HBCU sector. To this end, the study's epistemological approach was anchored in the social constructivist tradition to construct knowledge, understanding, and meaning through human interactions (Creswell \& Poth, 2018).

\section{Population and Sample}

Using a maximum variation sampling approach, which is about understanding how a phenomenon is understood from a diverse set of individuals (Creswell \& Poth, 2018), participants of this study were college and university leaders, those who hold or previously held formal academic leadership titles (e.g., Deans, Vice Presidents, former Presidents, and a student government president) at HBCUs and scholars who research HBCU leadership. In total, 19 participants were interviewed for this study. Overall, the participants have over 65 years of experience studying or serving as HBCU leaders and some of the HBCU presidents included in this study have been successful during their tenure of leadership at their institutions. We elicited the perspectives of a variety of types of interviewees because we felt it important to gain various insights from a diversity of voices that viewed the HBCU presidency differently based on their positionality. For instance, we were particularly interested in the inclusion of student leadership in higher education. We felt it important to include the voice of a leader who had demonstrated significant impact regarding institutional change and governance of their institution.

We recruited participants through the use of a variety of resources

(e.g. professional networks, university websites, and academic and 
professional conferences). Announcements about the study were distributed through e-mail Listservs. Additionally, some participants were selected using snowball sampling (i.e., asking those who joined the study to recommend others who might meet our criteria). When potential participants replied to the invitation to participate in the study, we sent them an in-depth explanation of the study, including recruitment materials, and an informed consent form. Participants were asked to provide their insights into issues pertaining to the HBCU presidency based on their experiences with presidents at their institutions, their research, anecdotal evidence based on what they have learned while being affiliated with HBCUs, and first-hand knowledge of past and current presidents in which they had interactions.

\section{Data collection}

Qualitative research underscores that dependability, transferability, credibility, and confirmability are important criteria for trustworthiness (Creswell \& Poth, 2018). To this end, multiple methods of data collection were used including curriculum vitas, biographical sketches of participants, and online and print media accounts of stories related to HBCUs to verify stories mentioned by participants. Each of the data sources apart from the interviews, were used to verify the backgrounds of each participant. Online and print media accounts were utilized to confirm the claims and stories of participants. Although, many of the stories are a matter of public record, we chose to not identify specific accounts, as not to further sensationalize these experiences.

All participants were interviewed over the phone. Both of us participated in most of the interviews. Less than five of those interviews were conducted by just one of us, however, both of us utilized the same interview protocol, reviewed each audio recording of each interview, and participated in the analysis process. These open-ended interviews lasted between 45 minutes to one hour. Audio equipment was used for the purpose of data collection. An interview script was used throughout the interview process. Copious and detailed notes were taken along with an audio recording of each interview. Summary notes were recorded in a journal directly following each interview.

\section{Data analysis}

To gain a better understanding of the phenomenon, we employed a thematic analysis and constant comparative method. Following each interview, we reviewed the transcripts and recording to conduct initial analysis using the constant comparative method to compare findings across the data collection phase of the research study (Creswell \& Poth, 2018). Using this method from an inductive approach, through open and axial coding, followed by thematic analysis, allowed us to interpret participants' reflections 
on their respective views of effective leadership at HBCUs. Further, this ensured reliability and trustworthiness of the findings. Words or phrases that were identified three times or more by interviewees were identified as codes. Once the codes were identified they were grouped into sections by overarching themes.

To respect the confidentiality of the participants, names were excluded from the final draft of this study. Strategies of member checking (returned transcribed interviews to participants to confirm that they accurately reflected their perceptions), peer-debriefing (provided a colleague with data from the study to share feedback regarding the soundness of our research process), and clarification of the researchers' positionality (described in the next section of this paper) to ensure the trustworthiness, validity, and reliability of the data (Creswell \& Poth, 2018). The findings have been presented using "thick," "rich," and descriptive data (Creswell \& Poth, 2018) to demonstrate the rigor and robustness of the findings.

\section{Positionality}

Demonstrating the reliability of the findings is a key aspect of the data collection and analysis process. The researchers in this study are aware of their own biases, values, and perspectives influence. The researchers noted their positionality as a form of reliability (Creswell \& Poth, 2018). Both authors identify as U.S. - born Black Americans. The first author attended and graduated from both a historically Black high school/ boarding academy and a HBCU. His future aspiration, which includes serving as a university president, makes this project relevant to his current and future professional goals. The second author is a faculty member at a HBCU. Among other topics related to HBCUs, he has written on college student success, Black male retention and persistence, and college and university leadership. He also is a higher education instructor and teaches in a program that prepares students for leadership and faculty roles at postsecondary education institutions.

Our identities and experiences in higher education, who attended, were affiliated with, and/or conducted research on HBCUs, created a unique lens and position to understand the contextual environment of HBCUs. Nevertheless, we allowed the findings to emerge independent of our biases. Member checking and peer debriefers also helped to make certain that the findings were accurately reflective of the participants' voices.

\section{Limitations}

Qualitative research often provides rich narratives that include the experiences, knowledge, and feelings of its participants. Despite these attributes, there are limitations surrounding qualitative research. One limitation is that the sample size of this study may not reflect the thoughts of all leaders and scholars affiliated with HBCUs. Moreover, we were not able 
to secure a large enough sample size to interview an equal distribution of participants based on their backgrounds (i.e. presidents, researchers, student leaders, etc.). Nevertheless, we have provided "rich," "thick" description so the reader may decide the extent to which this study is transferable to their institutional context. Finally, given that HBCUs are not monolithic in size, scope, and stature, while they face many of the same problems and challenges, the findings of this study may not be applicable to all HBCUs.

\section{RESULTS}

Participants identified multiple unique manifestations of effective leadership at HBCUs. Though participants mentioned a variety of factors germane to effective leadership of HBCUs, this study analyzes primarily responses that can be considered thematic. These responses fell into two categories: experiential skills (including managing finances and fundraising, academic community building, having business skills, having good communication skills, managing multiple constituencies, seeking input and teamwork, and innovative), professional knowledge (understanding institutional mission, cultural/institutional understanding, and professional experience).

\section{Experiential Skills}

\section{Managing Finances and Fundraising}

One of the most widely cited skills that participants felt that effective HBCU leaders needed to have was generating and managing financial resources. One scholarly expert, Imani summarized this sentiment when she stated:

HBCUs because they tend to have lower endowments and smaller endowments than their predominantly White counterparts ... I think a president that is able to ensure that not only is this institution financially strong, but is also finding avenues and ways to grow their endowment ... And to bring in resources into the institution and constantly, and seeing those resources grow. I think that, that is a president that's successful.

A dean, Ebony, expressed that HBCUs tend to be resourced challenged. Therefore, leaders should be able to provide a vision that would compel external and internal constituents to support the institution financially: HBCUs tend to be "resourced-challenged" so we need individuals that have linkages beyond their university's walls. I think the presidents that fumble, don't have those linkages. They don't have "external legitimacy" and they don't have "internal legitimacy.". . . What I mean by external legitimacy is the ability to communicate a vision and attract funding. 
Willie, a scholarly expert and former HBCU president, stated it succinctly, "One needs to understand something about business and good fund-raising skills." Darryl, an executive leader, shared that financial leadership not only rest on the shoulders of presidents, but other leaders within these institutions have a responsibility to ethical fiduciary management of resources: "There are things like fiduciary responsibility. Successful institutions, successful leadership are presidents or leadership management teams that are able to manage the fiscal responsibility [of their institutions] ...Fiduciary responsibility is the core."

Although each participant described the need for presidents to have strong financial management and fundraising skills in a different way, it was evident participants felt that managing finances and fundraising were core functions to effective leadership for an HBCU president.

\section{Academic Community Building}

Another area of effective leadership for HBCU leaders that was identified was academic community building. Andre, a scholarly expert, shared:

A president that is able to build a strong community across the board at that institution and really get them to align their mission together to build stronger connection and community with each other [should be considered successful] . . . And so that includes students, that includes alumni, that includes faculty that are there, staff that are there. People that help to fund the institution, so that means investors, and the community around you.

The above quote reveals that academic community building is not restricted to members of a HBCU that live and work on the campus. It also includes, alumni, friends of the institution, donors and the members of the local community. Each constituency plays an important role in the advancement of the academic community.

Another executive leader, Dominique said:

I think of leadership generally as inspiring or encouraging or providing a pathway, a means to where people who are part of an institution or either employed directly/indirectly or who consider themselves to be a part of the environment of an institution, the family of an institution. If they generally feel like this is their institution that's worthy of their time, their resources, their money, then I start to think that this is a place, this is place where good leadership is occurring.

Academic community building has become a key part of the role of HBCU presidents. Many HBCU leaders understand that for their institutions to be successful they need to break down silos across various constituency groups 
and develop more cooperative relationships between them for the overall advancement of their institutions.

\section{Business Skills}

Several participants mentioned the importance of business skills as a necessity for HBCU leadership skills. Business skills were defined as those skills required to manage a large organization, involving hiring and personnel decisions, general management, delegation of tasks, and maintenance of key relationships. Although each participant discussed business skills differently, participants generally agreed that business skills involved a strategic mindset. This was different than financial management and fundraising as the focus was on human capital management and leadership.

Alexis, a scholarly expert, stressed that to be an effective leader, "One needs to understand how to assemble a leadership team." In a similar vein, another scholarly expert also advocated gathering input from other stakeholders across the university:

I think some of the best leaders are those that acknowledge the situation and the use all of the kind of human resources that they have and their creativity to bring success to their institutions. So that would not only be presidents, but also anybody else working there.

Xavier, a current HBCU president, advocated for leaders to receive support from various constituencies related to their campuses so that they can do their jobs effectively:

The ability to empower responsibility for his or her areas of leadership. I think also to be effective and to be successful, a campus leader has to do a good job in selecting competent team members who, understand the job to which they're being hired and can do that job effectively...people should be hired because of their mental competence and their understanding of the position for which they're being hired.

Darryl summed up well the theme of business skills needed for an effective leader by noting, "Certainly, management is the "hallmark" I think of great institutions. How well are they managed with regard to human resources - the operation of an institution." Participants described that effective leaders at HBCUs are those who have basic management skills, understand the core business of the institution, and focus on hiring the right people.

\section{Good Communication Skills}

Communication skills were one of the most often mentioned characteristics of an effective leader, particularly because they have to engage multiple constituencies. Ebony stressed the importance of HBCU leadership communicating their goals: 
"I think another [a] big piece is being able to communicate what is coming "around the curve" and really galvanize all of the different stake-holders whether it's alumni, students, faculty and being able to galvanize them around that goal."

Malik, a current HBCU president, mentioned specifically the importance of communicating well with students and faculty:

That means understanding the students that I serve and have the students understand me. Understanding the faculty that I work with, having the faculty understand me, and being in a position where I'm always speaking what I consider to be, what I consider to be the truth. Reginald, an executive leader and scholarly expert, discussed the importance of communicating well with the board of trustees:

Making sure that people are on board, that communication is there, because a lot of times in HBCUs there is a "communication breakdown." And that's where the problems lie. So, rumors get started, the morale goes down and so it's more about a lot of times motivating and keeping people informed and being trustworthy, that the leaders are trusted. The leader that is not trusted by the employees it's going to filter down to the students to all of the other stakeholders as well. . . They must possess communication skills, as well as be a good communicator can go a long way. . . A lot of times, one hand doesn't know what the other hand is doing and so they're duplicating services or duplicating something that why reinvent the wheel when they don't have to? . . . Having open communication where they would have weekly meetings or even e-mails to go out to the keep people informed about what's going on in their areas creates less competition.

In summary, it is the job of the president to communicate effectively with all constituencies related to the institution. Participants stated that honesty and transparency was important in communicating the direction the institution was going in. Various constituencies do not like to be blindsided with negative news. Communicating clearly and effectively on a continuous basis helps with this goal.

\section{Managing Constituencies}

Similar to effectively communicating to various constituencies, managing these groups is very important. Terrance, an executive leader, explained: "Well one thing that comes to mind is the understanding of higher education, meaning that higher education is very much an organization or an entity that focus on consensus for the most part." Kathryn, a current HBCU dean, mentioned how important establishing good rapport with various constituencies were for effective leaders: 
Good rapport, and I say that because I've seen, or I've been a part of organizations that the president didn't have a good rapport with staff, but have a good rapport with the community and I really think that's criminal to the organization to hire someone who does not have a good rapport with the community or with the employees. The next trait or next characteristic is being able to build relationships. I think that can also be a part of having a good rapport as well, but I think that a leader has to be a person that's able to build relationships. Because that's just what it's all about, building relationships to help push the vision on the institution.

An important part of $\mathrm{HBCU}$ presidents managing various constituencies is ensuring that they are cultivating positive relationships with them by keeping them informed but also establishing a positive rapport. Given the fiscal challenges that many of these institutions face, managing relationships becomes key. When challenging times impact a campus, a president that has already established good rapport with various constituencies may be extended the benefit of the doubt because trust has been earned and established.

\section{Seeking Input/Teamwork}

Establishing an open environment where various constituencies feel heard and valued was consistently mentioned as important. Many felt that this would lead to a collegial atmosphere. Dominique shared her experience with facilitating this type of organizational leadership:

I think my philosophy has continued to evolve, but I've always been a "participatory leader." In that I like input, I seek input with the full understanding that [all voices should be respected] and I believe in the team approach and that's why I engage in participatory leadership... My role as a [previous president] was to be the team leader, which means I had the responsibility oftentimes in making final decision, but I did so with a presidential cabinet... Again, I am a participatory leader that believes in the team effort. My cliché on that is "I don't care how good the quarterback is, he cannot win the game, it takes the entire team members."

Cassandra, a former HBCU president, described it as a form of shared governance. She went on to say how important it is to hear a variety of voices and opinions through various strategies:

I believe very much that shared governance is necessary to move institutions forward. I think that it helps in terms of attracting scholars that are needed to advise and produce students for the global marketplace that we're in. . I think that it's very much necessary to have leaders who use more of what I called a "grass-roots" method. . . Where they are listening to the stakeholders across [the campus 
community] ... And trying to come to some shared consensus to make decisions.

Darryl summed this theme up by sharing how effective leaders build great teams: "I think really effective leaders now are the people who can build really successful teams of people to collaborate and be able to use technology in ways that can develop new solutions to old problems." Participants shared that seeking input from various members of the academic community at different levels within the community is key to the success of a HBCU presidency. Great ideas are not solely the purview of those a part of the institutions or sit on its cabinet. Therefore, seeking wise counsel and advice from a diverse array of informed individuals is important for HBCU leaders.

\section{Innovation}

Participants felt innovation was another skill for an effective leader to possess. Willie explained:

I think that we live in a world of constant change, a lot of it driven by technology. If you're not re-inventing yourself - you're falling behind. So, we need leaders who understand that as number one and we need board of trustees who understand that also.

Alexis, a scholarly expert, underscored that assessment by saying:

It's focused on being really innovative rather than braving the status quo. . . I think that successful leadership is really creative and realizes that rather than complaining about the situation realizes that you have to be more creative when you don't have as many resources.

Shanice, an executive leader, shared that innovation is needed given the current financial pressures being felt across the higher education sector, "I think the person has to be innovative, particularly now in higher education in terms of the shifts in enrollment and the rapid shifts in general." Malik specifically talked about the importance of those in the presidency thinking in an innovative manner:

I think effective presidential leadership is closely akin to running a marathon. Where the runner grabs the baton from the previous runner, in this case the current president grabs the baton from the previous president. . . And that baton must be handed off in a very smooth manner, you can't drop it, (chuckled) you can't stumble. And when that former president handed the baton off, that person then exits the race and basically cheers for the person who is running his or her leg. And it is the responsibility of the person who has the baton who's running his or her leg. . . To run it swiftly, faster, more agility than what was run before him or her. So that when you get ready to pass the baton off to the next person, the institution is further along around the track. 
Many participants discussed the notion of innovation. It was expected that an effective HBCU president would not see challenges as paralyzing but would find ways to innovate and address the issue head-on. However, participants suggested that innovation was not the sole responsibility of the president, but it was their responsibility to facilitate a culture of innovation among their various constituencies.

\section{Professional Knowledge \\ Institutional Mission}

As discussed, institutional mission is particularly important to HBCUs. Participants felt that effective leaders in this sector must have a strong understanding of the unique mission of these institutions. Laila, a HBCU scholarly expert, described how mission should drive decision-making and not leaders' personal agenda:

It's more focused on students [more] than it is on self. . I think that it's focused on doing the best with the students that you have and not trying to compete with institutions that have a different kind of students. . . But embracing your mission and focusing on those students.

Cassandra stressed the importance of humility and a collaborative nature:

Successful leadership...needs to be mission-driven. So, if it's mission-focused and mission-driven, then presidents and all the stake-holders involved are able to know what they are there for. Which is to take hold of that mission again from the employees to every stakeholder, the students, the family all of that, and then to having a good leader who can communicate that mission.

The understanding of and commitment to the unique mission of HBCUs is important to the success of presidencies at these institutions. Given its unique niche and role within the American higher education landscape, it is important that those who lead within these institutions have a personal respect for the mission of these institutions and ensure that members of various constituencies that are affiliated with HBCUs do the same.

\section{Cultural/Institutional Understanding}

Participants discussed a lot about the need for HBCU leaders to understand the unique $\mathrm{HBCU}$ culture along with the specific campus culture of their institution. Maurice, a scholarly expert and executive leader, shared it this way:

You have to understand the culture, you have to understand the players...I think culture is very important part of understanding what you do at an institution and what you will be able to do at an institution. 
Dominique provided examples of what was meant by the theme of cultural and institutional understanding, specifically outlining the context the modern HBCUs find themselves in:

If you just look at where we are now in terms of the country's political, social and economic backdrop and you look at what HBCUs represent. Then it's a very challenging and maybe significant point in the institution's history, the institution's collective history. There are lots of folks out there who are critics of HBCUs who would like to see them closed, don't see their purpose and talking so forth. Yet there's a certain clear constituency that the institutions have served and can continue to serve. I think that effective leadership now recognizes that first element that I was talking about which is that you're operating in a larger particularly political and economic dynamic now. . . If you're dealing with a different population and a different reality, maybe what you want to do is establish your brand you know, find a common vernacular, in a way that distinguishes you from the other institutions. . Y You know um, our institutions again are under such attack now...to do everything that other institutions do in the same way other institutions do them, doesn't give us what we need which is again that distinctiveness, that recognition point that the students that we want to enroll are going to have us as their first choice!

Laila acknowledged that a focus on mission and tradition can be positive:

I think at HBCUs, one of the challenges and why there could be kind of a transactional model and perhaps has been so prevalent in some institutions is because in a positive sense there is such a great degree of respect for tradition. I mean these are historic institutions with incredible history, with incredible records of success, so meaningful to various communities. So, what worked in the past is tradition, this pride may in some ways be a wonderful thing that builds on that sense of honor and pride and respect.

HBCUs have a unique culture as one of the only sectors in American life outside of the Black church that is predominantly led and operated by African Americans. It is important that those who lead these institutions understand the challenges that these institutions have had to endure. Their success, despite these obstacles, has cultivated a unique culture at HBCUs. It is important for any HBCU president to acknowledge and respect that and build upon its legacy.

\section{Knowledge of Higher Education}

The knowledge gained from working in various capacities in higher education was seen as important by participants in this study. Darius, a current president, expounded on this notion below: 
I think an effective leader at a HBCU is one who has gained the benefit of their sense of going through the ranks in academia Assistant Professor, Associate Professor, Full Professor, Department Chair, Dean, and Vice President. And I say that because I think in order to effectively lead individuals - you have to understand the nature of the work that they do, and there's no better way before a campus CEO to do that, they actually have to put himself or herself served in those roles.

Terrance also supported that sentiment when he shared:

Well first and foremost the person who understands higher education, and I think I might be a little traditional in terms of my thinking. But a lot of folks who assume these positions may not have a really complete, comprehensive and exhaustive type of education of the sector. And as a result, some of the decisions that are made could have more corporate ties and rooted in business which is a component of higher but not the full component. So as a result, I think, first and foremost that person should have a strong education on higher education.

Some of the participants had a healthy skepticism of those currently in presidential roles or are seeking such positions at HBCUs that did not have higher education experience. Although there was a general preference that HBCU graduates who had gone on to serve in various academic and leadership capacities serve as presidents, there was an openness to having higher education leaders with other experiences to serve as presidents. However, there was a general preference for leaders to train in higher education before serving as president at a HBCU.

\section{DISCUSSION AND CONCLUSIONS}

Data from this current study emerged from a larger study that examined contemporary leadership practices of $\mathrm{HBCU}$ presidents. One of the emerging themes focused on the participants' perceptions of effective leadership strategies of $\mathrm{HBCU}$ presidents. Participants identified two categories reflective of effective leadership practices for HBCU presidents. The first category denoted experiential skills, which includes managing finances and fundraising, business acumen, demonstrating good interpersonal skills, innovation, and working collaboratively across multiple constituencies. The second category focused on professional knowledge, which is comprised of having a keen understanding of the institution's mission and culture.

Esters and colleagues (2016) identified many of the same practices of effective leadership practices for HBCU presidents that emerged from this current study. For example, both this current study and Esters et al.'s (2016) report highlighted the importance of engaging in collaborative leadership approaches, being visionary, forward, and innovative thinking, knowledge on 
fundraising and financial management, having some background knowledge on managing larger, complex organizations, working well and maintaining healthy relationship across a variety of constituencies (governing board, faculty, staff, students, and alumni), and hiring the right people.

Other studies have acknowledged the aforementioned leadership practices and their linchpin to the effectiveness of leadership for HBCU presidents (Freeman et al., 2016). For example, in their article, based on interviews with 21 participants, some of whom were $\mathrm{HBCU}$ presidents and board members, Freeman et al. (2016) explained that in order for HBCU presidents to be successful in the $21^{\text {st }}$ Century, they need to be visionary, have the ability to communicate well and across diverse audiences, and maintain positive and healthy relationships with the governing board, and students. Freeman and colleagues also noted that HBCU presidents should use social media to tout the successes occurring at their institutions, adopt a collaborative leadership disposition, and engage in fundraising as well as using data to guide decision making.

Despite this, data from this current study revealed some differences in effective leadership practices of HBCU presidents that were not specifically discussed in Esters et al.'s (2016) report or in studies by other researchers (e.g., Freeman \& Gasman, 2014; Freeman et al., 2016). For example, in Esters et al.'s report, they delineated HBCU presidents should not only possess knowledge about the local, state, and federal policy decisionmaking and funding process, but also engage in social media to control the narrative about their institution, pursue private and public grant opportunities, stay apprised of higher education issues and policies, and understand the salience of student engagement. While participants in this current study did not explain how the aforementioned factors would help to facilitate leadership success for HBCU presidents, they acknowledged HBCU presidents should not only understand the institutional mission and culture, but also engage in decision-making that reflects fidelity to those "professional knowledge" areas (i.e. institutional mission and culture) of the institution. Similarly, while more HBCU presidents are emerging from nontraditional paths (Willis \& Arroyo, 2018), participants in this current study believed HBCU presidents should come from the traditional rank of the academy (i.e., serving as a professor and working their way up the ranks).

Moreover, participants of this current study believed HBCU presidents should adopt tenets of Servant or Transformational leadership. It is important to note that while Ester's et al.'s (2016) report does not specifically discuss Servant or Transformational leadership directly, they do discuss characteristics of these leadership styles, such as adopting a collaborative leadership approach, developing positive working relationship across institutional stakeholders, and using effective communication skills, and their centrality to the success of HBCU presidents. Nevertheless, other 
scholarship - be it empirical or anecdotal-has posited that Servant or Transformational Leadership are ideal styles for HBCU presidents (Gasman, Lockett, \& Esters, 2018; Myrick-Harris, 2014). In particular, Gasman et al. (2018) explained how Michael Sorrell, president of Paul Quinn, has adopted a Servant Leadership style, which has not only empowered faculty and students, but also helped the institution to soar. Similarly, in a study of presidents of private HBCUs conducted by the United Negro College Fund, participants explained they believed characteristics of Transformational Leadership are critical to success for HBCUs. However, many admitted using a combination of Transactional and Transformative styles when their institutions encountered challenging times in the late 2000s (Myrick-Harris, 2014).

The characteristics participants in this current study identified as contributors to effective leadership of HBCU presidents are salient factors that propel the success of institutions and organizations in general. Despite this, discussing these factors in the context of HBCUs is particularly critical for several reasons. First, consistent with the anti-deficit approach of this article, the findings focus on factors that promote the success of HBCU presidents as opposed to fueling the narrative about poor leadership practices at HBCUs. Second, the findings also provide important context for effective leadership practices of HBCUs, which might help to strengthen the capacity of HBCU leaders and contribute to the sustainability of these institutions. This, of course, is utterly important, as discussed previously, unlike other MSIs, once a HBCU is closed, another one cannot be established.

\section{IMPLICATIONS AND RECOMMENDATIONS}

This current study has found two categories are critical for effective leadership of HBCU presidents - Experiential Skills and Professional Knowledge. Embedded in each of these categories are critical strategies that improve the leadership of HBCU presidents. While many of these practices have been discussed in the extant literature, this study has provided further insight into effective leadership of HBCU presidents. In this regard, this current study expands and complicates our understanding of effective leadership of presidents at HBCUs.

With this being the case, this study provides several implications for research and practice. First, in terms of research, given the leadership challenge facing HBCUs, which has contributed greatly to the demise of some of these institutions, more research on effective leadership practices among HBCU presidents is needed. There are only a handful of articles/reports, many of which are anecdotal, that have examined effective leadership for presidents of HBCUs. Given the linchpin between successful leadership and the sustainability of HBCUs, this research needs to involve multiple approaches, such as qualitative, quantitative, and mixed methods. Specifically, more 
research is needed that involve case studies of successful HBCU presidents. With the understanding that HBCU are not monolithic, when it comes to leadership, these case studies might provide inspiration, guidance or a template for HBCU leaders seeking to improve their leadership practices. Along these same lines, there is a scant of literature on Servant and Transformational Leadership situated within the context of the HBCU presidency (Transforming Leadership, 2015). Since research from this current study and other sources (e.g., Gasman et al., 2018) has indicated that these leadership styles help to facilitate successful leadership outcomes for HBCU presidents, additional studies on these, and perhaps other leadership styles, should be conducted.

Given that HBCUs and their leadership structure are not a monolith, it may be important for future researchers to consider conducting future studies based on various institutional types within HBCUs, differences by gender of presidents, various leadership roles, etc. HBCUs are a treasure trove of opportunity for leadership exploration. The existing studies have only begun to provide insight into the complexity of leadership that has been, and continues to be, displayed at these venerable institutions.

In terms of practice, organizations and firms that prepare and groom future $\mathrm{HBCU}$ leadership in general and HBCU presidents specifically, should work in tandem with the research community, and HBCU themselves, to expose these aspiring leaders to the latest research on effective leadership practices for HBCU presidents. Specifically, given that research from this current study and others (e.g., Esters et al., 2016; Freeman \& Gasman, 2014) has ostensibly indicated that visionary, "forward" thinking, and innovative leadership practices, along with knowledge on fundraising, collaboration, the ability to manage complex organization, and the ability to communication and maintain positive relations across a variety of constituents, contribute significantly to the leadership efficacy of HBCU presidents, HBCU leadership preparatory organizations should help participants cultivate and maximize these skills. It is hoped that this manuscript helps to inspire and inform those who prepare aspiring HBCU presidents and those interested in serving as a HBCU president with scholarship that will assist in developing the next generation of successful HBCU presidents.

\section{REFERENCES}

American Council on Education (ACE)/United Negro College Fund (UNCF) (2019). Public and Private Investments and Divestments in Historically Black Colleges and Universities ( $\left.1^{\text {st }} \mathrm{ed}\right)$. Washington, DC.

American Council on Education (ACE) (2017). American College President Study. ( $8^{\text {th }}$ ed. $)$. Washington, DC.

Association of Governing Boards of Universities and Colleges (AGB) (2014). Top Strategic Issues Facing HBCUs, Now and into the Future ( $1^{\text {st }}$ ed). Washington, DC. 
Commodore, F. (2017). The tie that binds: Trusteeships, values, and the decisionmaking process at AME-Affiliated HBCUs. The Journal of Higher Education, 89(4), 397-42.

Creswell, J. W., \& Poth, C. N. (2018). Qualitative Inquiry and Research design: Choosing among five approaches $\left(4^{\text {th }}\right.$ ed.). Sage.

Esters, L. T., Washington, A., Gasman, M., Commodore, F., O’Neal, B., Freeman, Jr., S., \& Jimenez, C. D. (2016). Effective leadership: A toolkit for the $21^{\text {st }}$ century historically Black college and university president. Philadelphia, PA: Penn Center for Minority Serving Institutions. Retrieved from https:// https://cmsi.gse.upenn.edu/sites/default/files/MSI LdrshpRprt R3.pdf

Ezell, J. L., \& Schexnider, A. J. (2010). Leadership, governance, and sustainability of Black colleges and universities. Trusteeship, 18(3), 25-28.

Freeman, Jr. S., Gasman, M., Commodore, F. \& Carter, C. (2016). Leaders wanted!: The skills expected and needed for a successful $21^{\text {st }}$ historically Black college and university presidency. Journal of Black Studies, 6, 1-16.

Freeman, Jr. S. \& Gasman, M. (2014). The characteristics of historically Black college and university presidents and their role in grooming the next generation of leaders. Teachers College Record, 116, 1-34.

Gasman, M. (2012). Vacancies in the Black college presidency. What's going on? Retrieved from https://www.chronicle.com/blogs/innovations/vacancies-inthe-black-college-presidency-whats-going-on/32204

Gasman, M., \& Hilton, A. (2012). Mixed motivations, mixed results: A history of law, interest convergence, and historically Black colleges and universities. Teachers College Record. V114 n7

Gasman, M., Lockett, W. A., \& Esters, L. (2018). Paul Quinn College: Servant leadership in action. In R. T. Palmer, D. C. Maramba, A. T. Arroyo, T. O. Allen, T. F. Boykin, \& J. M. Lee Jr. (Ed.), Effective leadership at minorityserving institutions: Exploring opportunities and challenges for leadership (pp. 81-91). New York, NY: Routledge.

Harper, S. R. (2010). An anti-deficit achievement framework for research on students of color in STEM. In S. R. Harper \& C. B. Newman (Eds.), Students of color in STEM: Engineering a new research agenda. New Directions for Institutional Research (pp. 63-74). San Francisco: Jossey-Bass.

Harris, A. (2017). HBCUs have a leadership problem. This group thinks it has the answer. The Chronicle of Higher Education. Retrieved from https://www.chronicle.com/article/HBCUs-Have-a-Leadership/240421?

Harris-Myrick, C. (2014). Perspectives on exemplary transformational leadership among presidents at historically Black colleges and universities. Washington, D. C: United Negro College Fund.

Kimbrough, W. (2016). 12 Years a HBCU President. Medium. Retrieved from 12years-a-hbcu-president-4310e1832597

Lomotey, K. \& Covington, M. (2018). HBCUs: Valuable-yet substantially impaired institutions. In R. T. Palmer, D. C. Maramba, A. T. Arroyo., T. O. Allen., T. F. Boykin., \& J. M. Lee (Eds.), Effective leadership at Minority serving institutions: Exploring opportunities and challenges for leadership (pp. 2145). New York, NY: Routledge. 
Maxwell, J. C. (2019). Five levels of leadership workshop. The John Maxwell Co.https://corporatesolutions.johnmaxwell.com/5-levels-of-leadershipworkshop/

Palmer, R. T., \& Freeman, S., Jr. (2019). Examining the perceptions of unsuccessful leadership practices for presidents at historically Black colleges and universities. Journal of Diversity in HigherEducation. Advance online publication. http://dx.doi.org/10.1037/dhe0000120.

Preston, D. \& Freeman, Jr., S. (June 26, 2019). The future of research and practice about MSIs. Diverse Issues in Higher Education. Retrieved from https://diverseeducation.com/article/148324/

Schexnider, A. J. (2017, December, 17). Struggling HBCUs must consider new options for survival (opinion). Inside Higher Ed. Retrieved from https://www.insidehighered.com/views/2017/12/20/struggling-hbcus-mustconsider-new-options-survival-opinion

Scott, D. W., \& Hines, R. (2014). Rethinking and reframing leadership of historically Black colleges and universities: A distributed perspective. Creative Education, 5, 132-1139.

Stuart, (2016). Willie D. Larkin resigns after 1 year as Gambling State University president. Diverse Issues in Higher Education. Retrieved from http://diverseeducation.com/article/85087/

Stuart, R. (2017, January). Expert: HBCUs' leadership instability unnerving for potential benefactors. Diverse Issues in Higher Education. Retrieved from https://diverseeducation.com/article/91429/

Suggs, E. (2019, January, 14). 18 HBCUs that didn't make it. The Atlanta JournalConstitution. Retrieved from https:/www.myajc.com/news/local/hbcusthat-didn-make/BnmRJgnxwnBV8yXqqtsWcP/

Transforming leadership at Minority-serving institutions. (2015). Retrieved from https://sa.umich.edu/content/dam/ncid-assets/nciddocuments/publications/Transforming\%20Leadership\%20Booklet.pdf

U.S. Department of Education (2020). What is an HBCU? White House Initiative on Historically Black Colleges and Universities. https://sites.ed.gov/whhbcu/one-hundred-and-five-historically-blackcolleges-anduniversities/\#: : text=The $\% 20$ Higher $\% 20$ Education $\% 20$ Act $\% 20$ of,agency \%20or\%20association \%20determined \%20by

Watson, J.E. (2013). Education experts concerned about the future of HBCUs as leadership frequently changes. Diverse Issues in Higher Education, 30(18), 7.

Willis, E. M. \& Arroyo, A. T. (2017). Student affairs administrators: A catalyst for HBCU transformation. In R. T. Palmer, D. C. Maramba, A. T. Arroyo., T. O. Allen., T. F. Boykin., \& J. M. Lee (Eds.), Effective leadership at Minority serving institutions: Exploring opportunities and challenges for leadership (pp. 21-45). New York, NY: Routledge.

SYDNEY FREEMAN, JR., PhD, is a tenured associate professor of adult, organizational learning, and leadership at the University of Idaho and has published over 80 publications. He completed Pine Forge Academy, which is one of four 
Historically Black Boarding Academies in the United States. In 2018, he was honored by the National Pine Forge Academy Alumni Association with its "Meritorious Award". Dr. Freeman also attended and completed his Bachelor of Arts in Interdisciplinary Studies at Oakwood University, wherein 2017 he was recognized as one of "the Alumni Faces of Oakwood University". And earned a master's and Ph.D. in Higher Education Administration at Auburn University in Alabama at the age of 26. Earlier this year he was named "the 2020 recipient of the College of Education Outstanding Young Alumni Award". And most recently, he was honored as one of the Accomplished Under 40 award recipients for 2020 by the Idaho Business Review. Email: sfreemanjr@uidaho.edu

ROBERT T. PALMER, PhD, is Department Chair and Associate Professor in the Department of Educational Leadership and Policy Studies at Howard University. His research examines issues of access, equity, retention, persistence, and the college experience of racial and ethnic minorities, particularly within the context of historically Black colleges and universities. Dr. Palmer's work has been published in leading journals in higher education, such as Journal of College Student Development, Teachers College Record, Journal of Diversity in Higher Education, Journal of Negro Education, College Student Affairs Journal, Journal of College Student Retention, The Negro Educational Review, and Journal of Black Studies, among others. Since earning his Ph.D. in 2007, Dr. Palmer has authored/ co-authored well over 100 academic publications. Email: robert.palmer@howard.edu

Manuscript submitted: June 2, 2020

Manuscript revised: September 17, 2020

Accepted for publication: October 10, 2020 